\title{
Total flavone of Abelmoschus manihot ameliorates Crohn's disease by regulating the NF-кB and MAPK signaling pathways
}

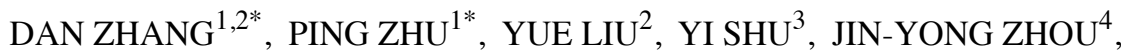 \\ FENG JIANG $^{1}$, TUO CHEN ${ }^{2}$, BO-LIN YANG ${ }^{1}$ and YU-GEN CHEN ${ }^{1}$
}

\begin{abstract}
${ }^{1}$ Department of Colorectal Surgery, The Affiliated Hospital of Nanjing University of Chinese Medicine, Nanjing, Jiangsu 210029; ${ }^{2}$ No. 1 Clinical Medical College, Nanjing University of Chinese Medicine, Nanjing, Jiangsu 210023; ${ }^{3}$ The Affiliated Hospital of Xuzhou Medical University, Xuzhou, Jiangsu 221000; ${ }^{4}$ Department of Central Laboratory, The Affiliated Hospital of Nanjing University of Chinese Medicine, Nanjing, Jiangsu 210029, P.R. China
\end{abstract}

Received September 26, 2018; Accepted April 19, 2019

DOI: 10.3892/ijmm.2019.4180

\begin{abstract}
Crohn's disease (CD) is a chronic relapsing form of inflammatory bowel disease, and its pathogenesis remains unknown. Total flavone of Abelmoschus manihot L. Medic (TFA), has been used as anti-inflammatory and myocardial ischemia protective drug. The present study aimed to explore the effects of TFA on CD and its underlying mechanism. We reported that TFA comprises eight flavone glycosides, including quercetin-3-O-robinobioside, gossypetin-3-O-glucoside, quercetin-3'- $O$-glucoside, isoquercetin, hyperoside, myricetin, gossypetin and quercetin. In vivo, TFA promoted the survival of 2,4,6-trinitrobenzene sulfonic acid (TNBS)-induced colitis in mice, decreased weight loss and increased colon length in a dose-dependent manner. Additionally, TFA notably ameliorated the inflammatory response in mice with TNBS-induced colitis as determined by histopathological analysis. In addition, the administration of TFA in mice with TNBS-induced colitis led to a significant decrease in the levels of cytokines in the sera and colon tissues; a significant decrease myeloperoxidase activity in the colon tissues was also observed. These findings may be associated with the suppression of the nuclear factor $-\kappa \mathrm{B}(\mathrm{NF}-\kappa \mathrm{B})$ and mitogen-activated protein kinase (MAPK) signaling pathways. In vitro, TFA significantly downregulated the expression of cytokines in lipopolysaccharide (LPS)-induced RAW264.7 cells. In addition, TFA suppressed LPS-induced activation of the NF- $\kappa$ B and MAPK
\end{abstract}

Correspondence to: Professor Yu-Gen Chen, Department of Colorectal Surgery, The Affiliated Hospital of Nanjing University of Chinese Medicine, 155 Hanzhong Road, Qinhuai, Nanjing, Jiangsu 210029, P.R. China

E-mail: yugen.chen@njucm.edu.cn

*Contributed equally

Key words: Crohn's disease, total flavone of Abelmoschus manihot L. Medic, inflammatory, nuclear factor- $\kappa \mathrm{B}$, mitogen-activated protein kinase signaling pathways in RAW264.7 cells. Our findings indicated that TFA could suppress the inflammatory response in mice with TNBS-induced colitis via inhibition of the NF- $\kappa$ B and MAPK signaling pathways. The results of the present study may improve understanding of the function of TFA and provide a novel theoretical basis for the treatment of CD.

\section{Introduction}

Crohn's disease (CD) is a chronic relapsing form of inflammatory bowel disease, which is typically characterized by transmural inflammation, lymphangiectasia, and lymphatic and fibrous tissue hyperplasia $(1,2)$. It is clinically characterized by segmental inflammatory injury of the digestive tract, which can involve any part of the digestive tract, and seriously affects the quality of life of patients (3). It has been suggested that dysfunctional regulation of the immune system of gastrointestinal tract was closely associated with CD (4). It is widely known that the imbalance of inflammatory mediators is an important mechanism underlying the pathogenesis of CD (5). Therefore, immune modulatory drugs have been widely utilized for the treatment of CD (6); however, maintaining the efficiency and the reducing severe side effects should be addressed.

In $\mathrm{CD}$, inflammatory cytokines, including interleukin (IL)-6, tumor necrosis factor- $\alpha$ (TNF- $\alpha$ ) and interferon- $\gamma$ (IFN- $\gamma$ ), are produced by infiltrating cells and macrophages, which serve an important role in colonic tissue destruction (7-9). In inflammatory cells, the inappropriate activation of nuclear factor- $\kappa \mathrm{B}(\mathrm{NF}-\kappa \mathrm{B})$, a key transcription factor, regulates the expression of the inflammatory mediators, which has been associated with the occurrence and development of CD (10). In addition, studies have demonstrated that the mitogen-activated protein kinase (MAPK) signaling pathway is critical in CD (11). MAPK signaling comprises p38, JNK and ERK, and regulates important biological processes, such as cell growth, cells apoptosis and inflammation (12-14). It was reported that the activity of p38 was notably increased in patients with CD (15). Additionally, the inhibition of stress-activated MAPKs could improve the clinical condition of patients (16). 
Abelmoschus manihot L. Medic is a traditional herbal medicine has been used as a neuroprotective drug for cerebral ischemic reperfusion injury (17). Total flavone of A. manihot L. Medic (TFA) is the main active ingredient, which has been used as an anti-inflammatory and myocardial ischemia protective drug (18-20). It has been demonstrated that TFA could decrease urinary albumin excretion in early-stage diabetic nephropathy (21). In addition, TFA has neuroprotective effects on neuronal damage, including cerebral ischemia injury (22); however, the role of TFA in $\mathrm{CD}$ and the underlying mechanisms remain unknown. In the present study, we studied the effects of TFA on a murine model of TNBS-induced colitis and a cells model induced by LPS, and its underlying mechanism.

Our study demonstrated that TFA could ameliorate the inflammatory response in mice with TNBS-induced colitis by inhibiting the $\mathrm{NF}-\kappa \mathrm{B}$ and MAPK signaling pathways. Therefore, the present study proposed that TFA may inhibit the pathogenesis of $\mathrm{CD}$ via the anti-inflammatory properties of TFA. These findings may provide insight into the function of TFA and its application in the treatment of CD.

\section{Materials and methods}

Drugs. Flowers of A. manihot L. Medic were collected from Jiangyan district of Jiangsu, by Professor Yu-Gen Chen. The specimen was stored at the Herbarium of Nanjing University of Chinese Medicine for future reference and verification. TFA was extracted from the flowers of A. manihot L. Medic by Nanjing University of Chinese Medicine. The extraction process of TFA was as follows: Three extractions with $70 \%$ alcohol for $50 \mathrm{~min}$ each at room temperature, and the yield was $\sim 35 \%$. The purity of TFA was $90 \%$. TFA was suspended in $1 \%$ carboxymethyl cellulose solution at different concentrations $(125,250$ and $500 \mathrm{mg} / \mathrm{kg})$.

High performance liquid chromatography (HPLC) analysis of TFA. A total of eight standards (purity >98\%) were purchased from Shanghai Yuanye Bio-Technology Co., Ltd. TFA was examined using a Waters 2694 series HPLC instrument (Waters Corporation). The sample was separated on a $\mathrm{C}_{18}$ column (4.6x250 mm,5 $\left.\mu \mathrm{m}\right)$ and the mobile phase gradient contained acidified water with acetonitrile (solvent $\mathrm{A}$ ) and phosphoric acid (solvent B, $0.2 \%$ ). The gradient program was performed as follows: $0-10 \mathrm{~min}, 86 \% \mathrm{~B} ; 10-15 \mathrm{~min}$, $92 \% \mathrm{~B} ; 15-25 \mathrm{~min}, 92 \% \mathrm{~B} ; 25-30 \mathrm{~min}, 81 \% \mathrm{~B}$; $30-65 \mathrm{~min}$, $81 \% \mathrm{~B} ; 65-70 \mathrm{~min}, 86 \% \mathrm{~B}$. Chromatography was performed at $30^{\circ} \mathrm{C}$ at a flow rate of $1.0 \mathrm{ml} / \mathrm{min}$ and aliquots of $10 \mu 1$ were analyzed.

Animals. A total of 60 female BALB/c mice (6-8 weeks old) with a body weight of 18-22 g were provided by Nanjing Medical University. All mice were housed in standard animal cages under specific pathogen-free conditions. The housing conditions were maintained at $22-23^{\circ} \mathrm{C}$, with a 12 -h light/dark cycle; mice had ad libitum access to food and water. In addition, mice were given 1 week to acclimatize to the facility prior to the start of experimentation. The present study was approved by the Institutional Ethics Committee of Nanjing University of Chinese Medicine.
Model establishment. For application of 2,4,6-trinitrobenzene sulfonic acid (TNBS), colitis was induced via intracolonic administration of TNBS. Briefly, $150 \mathrm{mg} / \mathrm{kg}$ TNBS in $48 \%$ ethanol was administered once every 7 days for a total of four treatments, while the normal group received sterile saline $(n=10)$. A catheter was inserted into the colonic cavity for $4 \mathrm{~cm}$, in which the TNBS solution was discharged, and the animal was held in the Trendelenburg position for $2 \mathrm{~min}$ to ensure contact with the intestinal mucosa.

Treatment. Mice were randomly assigned to six treatment groups ( $\mathrm{n}=10)$, including the control (distilled sterile saline only), TNBS, positive drug salazosulfapyridine (SASP), $125 \mathrm{mg} / \mathrm{kg}$ TFA, $250 \mathrm{mg} / \mathrm{kg}$ TFA and $500 \mathrm{mg} / \mathrm{kg}$ TFA treatment groups. Details of treatment were presented in Table I; the drug was intraperitoneally administered. SASP is the first-line therapy for the induction and maintenance of remission in patients with ulcerative colitis and those with CD, and is widely used in China (23). Furthermore, SASP was used as a positive control in ulcerative colitis and $C D$ research $(24,25)$. In addition, the weight and common symptoms of $\mathrm{CD}$, including blood in the stool, abdominal pain and constipation of mice in every group was analyzed weekly. However, any mice that were scored 4 for bleeding (26) or had diarrhea were euthanized. Furthermore, mice were euthanized at day 28; blood samples were collected from the tail vein and centrifuged at $12,000 \mathrm{x}$ g for $5 \mathrm{~min}$ at $4^{\circ} \mathrm{C}$ to obtain serum. The distal colon was carefully excised and the colon was weighed and measured length.

Assessment of disease activity. During the experiment, body weight, stool features, and fecal occult blood were recorded daily. The disease activity index (DAI) was calculated by scoring weight loss, stool features and fecal occult blood based on a previously described scoring system (Table II).

$H \& E$ staining. Colonic segments were excised and washed in PBS, fixed in $4 \%$ formaldehyde for $30 \mathrm{~min}$ at room temperature, embedded in paraffin and sectioned $(5 \mu \mathrm{m})$ and finally stained with H\&E for visual analysis. At least three different sections were examined for each group using a light microscope to assess the histopathological changes at x200 magnification.

Myeloperoxidase (MPO) enzyme activity assay. Colonic tissues were cut into small pieces and homogenized on ice with normal saline. The levels of MPO were determined using commercial assay kits (Alpha Diagnostic International). Briefly, colon tissues were weighed, cut into fine pieces, and mixed with $200 \mu \mathrm{l}$ radioimmunoprecipitation assay (RIPA) lysate per $20 \mathrm{mg}$ tissue. The samples were homogenized using a glass homogenizer. Following lysis, the samples were centrifuged at $10,000 \mathrm{x}$ g for $3 \mathrm{~min}$ at $4^{\circ} \mathrm{C}$ to obtain the supernatant. The protein concentration was determined using a Bicinchoninic Acid Protein Assay Kit (Beyotime Institute of Biotechnology). Subsequently, MPO activity was investigated according to the manufacturer's protocols of the kit employed. MPO activity of the supernatants was determined and expressed as units per gram of total protein $(\mathrm{U} / \mathrm{g})$.

Cell culture. The RAW264.7 cell line was purchased from the Shanghai Cell Bank of Chinese Academy of Sciences. 
Table I. Treatment in different groups.

\begin{tabular}{ll}
\hline Groups & \\
\hline Control & Sterile saline/day for a total of 28 days \\
TNBS & TNBS enema/7 days for a total of four treatments + sterile saline $/$ days for a total of 28 days \\
SASP & TNBS enema/7 days for a total of four treatments $+\mathrm{SASP} / \mathrm{d}$ for a total of 28 days \\
$125 \mathrm{mg} / \mathrm{kg} \mathrm{TFA}$ & TNBS enema $/ 7$ days for a total of four treatments $+125 \mathrm{mg} / \mathrm{kg} \mathrm{TFA} /$ day for a total of 28 days \\
$250 \mathrm{mg} / \mathrm{kg} \mathrm{TFA}$ & TNBS enema/7 days for a total of four treatments $+250 \mathrm{mg} / \mathrm{kg}$ TFA $/$ day for a total of 28 days \\
$500 \mathrm{mg} / \mathrm{kg} \mathrm{TFA}$ & TNBS enema/7 day for a total of four treatments $+500 \mathrm{mg} / \mathrm{kg} \mathrm{TFA} /$ day for a total of 28 days
\end{tabular}

SASP, Salazosulfapyridine; TFA, total flavone of Abelmoschus manihot L. Medic; TNBS, 2,4,6-trinitrobenzene sulfonic acid.

Table II. Scoring of disease activity index.

\begin{tabular}{lccc}
\hline Score & Body weight loss $(\%)$ & Stool feature & Fecal occult blood \\
\hline 0 & 0 & Normal formed & Negative \\
1 & $1-5$ & & Positive \\
2 & $5-10$ & Loose stool & Gross bleeding \\
3 & $10-20$ & Diarrhea & \\
4 & $>20$ & &
\end{tabular}

Adapted from ref. (22).

RAW264.7 cells were cultured in Dulbecco's Modified Eagles medium (Gibco; Thermo Fisher Scientific, Inc.) with $10 \%$ fetal bovine serum (FBS; Gibco; Thermo Fisher Scientific, Inc.) in a humidified $5 \% \mathrm{CO}_{2}$ atmosphere at $37^{\circ} \mathrm{C}$.

Cell Counting Kit-8 (CCK-8) assay. RAW264.7 cells $\left(1.0 \times 10^{4} /\right.$ well $)$ were seeded in 96 -well plates and incubated for $24 \mathrm{~h}$ at $37^{\circ} \mathrm{C}$. Then, LPS (Gibco; Thermo Fisher Scientific, Inc.) in the presence or absence of various doses of TFA (aforementioned) were added into cells. After $24 \mathrm{~h}$ of culture, $10 \mu 1$ of CCK-8 solution (Dojindo Molecular Technologies, Inc.) was then added to each well. After incubation at $37^{\circ} \mathrm{C}$ in $5 \% \mathrm{CO}_{2}$ for $1 \mathrm{~h}$, cell viability was evaluated with a microplate reader (Bio-Rad Laboratories, Inc.), and the optical density at $450 \mathrm{~nm}$ was measured.

ELISA. Colon tissues were cut and weighed. The samples were lysed and homogenized using a glass homogenizer. RAW264.7 cells were treated with LPS in the presence or absence of various doses of TFA. Following lysis, the samples were centrifuged at $10,000 \times \mathrm{g}$ for $5 \mathrm{~min}$ at $4^{\circ} \mathrm{C}$ to obtain the supernatant. The supernatants of RAW 264.7 cells were collected and centrifuged $(10,000 \mathrm{x} \mathrm{g}, 5 \mathrm{~min})$ at $4^{\circ} \mathrm{C}$. The concentration of cytokines in the colonic tissues and cell supernatant were determined by ELISA for mouse TNF- $\alpha$ (ab208348, Abcam), IFN- $\gamma$ (ab100689, Abcam), IL-6 (ab100712, Abcam), IL-1 $\beta$ (ab100704, Abcam), IL-12 (ab236717, Abcam), IL-17 (ab100702, Abcam) and IL-10 (ab108870, Abcam) following the manufacturer's instructions. Briefly, $100 \mu 1$ of 2-fold diluted Standard, $80 \mu 1$ of Assay Buffer (included in the kit) and $20 \mu 1$ sample was added to the sample well. A total of $50 \mu 1$ of the diluted corresponding antibodies were added to each well and incubated at room temperature for $2 \mathrm{~h}$ on a microplate shaker set at $300 \mathrm{rpm}$. Then, $100 \mu 1$ of diluted Streptavidin-horseradish peroxidase was added to each well and incubated at room temperature for $0.5 \mathrm{~h}$ on a microplate shaker set at $300 \mathrm{rpm}$. Subsequently, $100 \mu 1$ of Substrate Solution was added to each well and incubated at room temperature for $10 \mathrm{~min}$ on a microplate shaker set at $300 \mathrm{rpm}$. Stop Solution (100 $\mu \mathrm{l})$ was added to each well. The 96-well microplates were analyzed using a PowerWave X340 microplate reader (BioTek China).

Western blotting. The total protein from the cell supernatant was extracted using RIPA lysis buffer. Protein was extracted and concentration was measured with a Bicinchoninic acid Protein Assay kit (Beyotime Institute of Biotechnology, Haimen, China). Equal amounts of protein $(30 \mu \mathrm{g})$ from each sample was separated by $12 \%$ SDS-PAGE and then transferred to a polyvinylidene fluoride membrane (EMD Millipore). Subsequently, the membrane was blocked in 5\% non-fat milk for $2 \mathrm{~h}$ at room temperature and incubated with primary antibodies overnight at $4^{\circ} \mathrm{C}$, including phosphorylated (p)-ERK1/2 (cat. no. 1150, 1:500; Cell Signaling Technology, Inc.), ERK1/2 (cat. no. 9103, 1:1,000; Cell Signaling Technology, Inc.), p-JNK (cat. no. 9250, 1:500; Cell Signaling Technology, Inc.), JNK (cat. no. 9252, 1:500; Cell Signaling Technology, Inc.), p-p38 (cat. no. 7946S, 1:1,000; Cell Signaling Technology, Inc.), p38 (cat. no. 6279S, 1:1,000; Cell Signaling Technology, Inc.), p-IкB $\alpha$ kinase (IKK) $\alpha / \beta / \gamma$ (cat. no. 1023, 1:500; Cell Signaling Technology, Inc.), IкB $\alpha$ (cat. no. 1146S, 1:1,000; Cell Signaling Technology, Inc.), p65 (cat. no. 8242, 1:1,000; Cell 

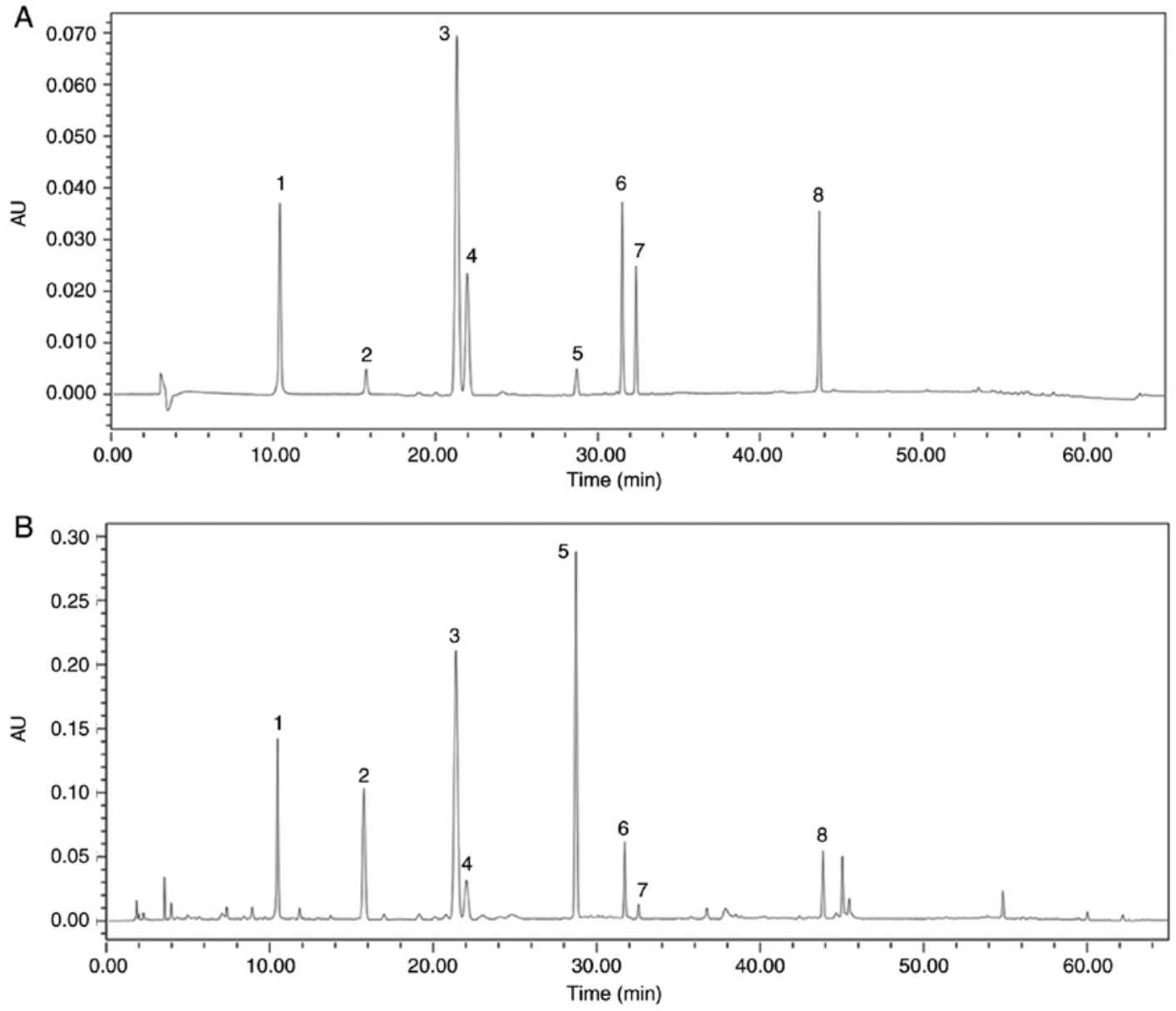

Figure 1. Chromatographic analyses of standards materials to TFA by high-pressure liquid chromatography. (A) HPLC chromatograms of standards (1, quercetin-3-O-robinobioside, 2, gossypetin-3-O-glucoside, 3, quercetin-3'-O-glucoside, 4, isoquercetin, 5, hyperoside, 6, myricetin, 7, gossypetin and 8, quercetin) and (B) TFA. TFA, total flavone of Abelmoschus manihot L. Medic.

Signaling Technology, Inc.), p-p65 (cat. no. 3033, 1:1,000; Cell Signaling Technology, Inc.), p52 (cat. no. 4882, 1:1,000; Cell Signaling Technology, Inc.) and p100 (cat. no. 3017, 1:1,000; Cell Signaling Technology, Inc.). Then, the membrane was probed with a horseradish peroxidase-conjugated secondary antibody (cat. no. 7076; 1:5,000; Cell Signaling Technology, Inc.) for $1 \mathrm{~h}$ at room temperature. The protein bands were visualized using ECL detection reagent (EMD Millipore) and the results were measured using ImageJ software 1.48 (National Institutes of Health).

Statistical analysis. GraphPad Prism 5.0 software (GraphPad Software, Inc.) was performed to analyze all data. The data were presented as the mean \pm standard deviation. One-way analysis of variance was applied to compare difference between multiple groups followed by a Tukey's post-hoc test. The differences between two groups were statistically analyzed using a Student's t-test. $\mathrm{P}<0.05$ was considered to indicate a statistically significant difference.

\section{Results}

TFA ameliorates weight loss and colon length. TFA mainly comprises eight flavone glycosides, which were characterized by HPLC, including quercetin-3-O-robinobioside,
gossypetin-3-O-glucoside, quercetin-3'- $O$-glucoside, isoquercetin, hyperoside, myricetin, gossypetin and quercetin (Figs. 1 and 2).

Initially, to determine whether TFA exhibits protective effects against colitis, the survival of mice with TNBS-induced colitis were investigated. The results demonstrated that TNBS significantly promoted mouse mortality, while the mice of the positive drug SASP or TFA groups notably promoted survival in TNBS-induced colitis (Fig. 3A). Subsequently, the effects of TFA on the body weight of mice were analyzed. The results demonstrated that TNBS notably promoted body weight loss, whereas treatment with TFA or SASP notably decreased this loss (Fig. 3B). Colon shortening is an indirect marker of inflammation (27). The result of the present study revealed that the colon length in the TNBS-induced colitis group significantly decreased compared with the control group, while treatment with TFA or SASP increased colon length (Fig. 3C). In addition, the DAI score, an indicator of the severity of colitis, is based on the results including weight loss, stool features and fecal occult blood (28). As presented in Fig. 3D, the DAI score for the TNBS group was significantly increased compared with the control group, while the DAI scores following treatment with TFA or SASP were significantly reduced compared with the TNBS group. In particular, there was no significant 
1<smiles></smiles>

4<smiles>O=c1c(O[C@@H]2O[C@H](CO)[C@@H](O)[C@H](O)C2O)c(-c2ccc(O)c(O)c2)oc2cc(O)cc(O)c12</smiles>

7<smiles>O=c1c(O)c(-c2ccc(O)c(O)c2)oc2c(O)c(O)cc(O)c12</smiles>

2<smiles>O=c1c(O[C@@H]2O[C@H](CO)[C@@H](O)[C@H](O)[C@H]2O)c(-c2ccc(O)c(O)c2)oc2c(O)c(O)cc(O)c12</smiles>

5<smiles>O=c1c(O[C@@H]2O[C@H](CO)[C@@H](O)[C@H](O)C2O)c(-c2ccc(O)c(O)c2)oc2cc(O)cc(O)c12</smiles><smiles>O=c1c(O)c(-c2ccc(O)c(O)c2)oc2cc(O)cc(O)c12</smiles>

3<smiles>O=c1c(O)c(-c2ccc(O)c(O[C@@H]3O[C@H](CO)[C@@H](O)[C@H](O)[C@H]3O)c2)oc2cc(O)cc(O)c12</smiles>

6<smiles>O=c1c(O)c(-c2cc(O)c(O)c(O)c2)oc2cc(O)cc(O)c12</smiles>

Figure 2. Chemical structures. 1, Quercetin-3-O-robinobioside; 2, gossypetin-3-O-glucoside; 3, quercetin-3'-O-glucoside; 4, isoquercetin; 5, hyperoside; 6 , myricetin; 7 , gossypetin; and 8 , quercetin.

difference between the effects of $500 \mathrm{mg} / \mathrm{kg}$ TFA and the positive drug SASP.

TFA improves histopathological abnormalities. The histological characteristics of the colon samples were evaluated by histopathological staining. The results indicated that mice maintained an integrated normal colonic structure in the control group, but mice in the TNBS-induced colitis group exhibited marked infiltration of inflammatory cells, loss of crypts, destruction of the mucosal layer and edema. In contrast, TNBS-induced colitis in mice pre-treated with TFA or SASP exhibited mild inflammation (Fig. 4A).

TFA inhibits MPO activity in colon tissues. MPO is an enzyme expressed by neutrophils and its activity is linearly associated with the infiltration of neutrophils in inflammatory tissues (29). In the present study, the activity of MPO in the TNBS-induced colitis group was significantly increased in colon tissues compared with the control group; however, treatment with TFA or SASP led to a significant inhibition of MPO activity in colon tissues; notably similar effects on MPO activity were observed with $500 \mathrm{mg} / \mathrm{kg}$ TFA and SASP (Fig. 4B).

TFA suppresses the production of inflammatory cytokines in mice with TNBS-induced colitis. In order to investigate the protective effects of TFA in mice with TNBS-induced colitis, sera and colon tissues were collected. The results demonstrated that TNBS significantly elevated the production of cytokines, including TNF- $\alpha$, IFN- $\gamma$, IL-6, IL-1 $\beta$, IL-12 and IL-17, in the sera and colon tissues compared with the control group. This was consistent with a previous report in which the levels of inflammatory cytokines, such as IFN- $\gamma$, IL-1, IL-6 and TNF- $\alpha$ were increased in the colon tissues of patients with CD (30). However, the administration of TFA or SASP in mice with TNBS-induced colitis led to a significant decrease in the production of TNF- $\alpha$, IFN- $\gamma$, IL-6, IL-1 $\beta$, IL-12 and IL-17 in the sera and colon tissues compared with TNBS treatment (Fig. 5). These results indicated that TFA may serve a role in the modulation of cytokine production under conditions of colonic inflammation.

TFA inhibits the activation of the NF- $\kappa B$ and MAPK signaling pathways. Activation of the NF-B and MAPK signaling pathways has been associated with the pathogenesis of CD (31). We evaluated the effects of TFA on the NF- $\mathrm{BB}$ and MAPK signaling pathways in mice with TNBS-induced colitis. The results of western blotting showed that the expression levels of I $\mathrm{B} \alpha$ and $\mathrm{p} 100$ in colon tissues were significantly increased in colon tissues in the TNBS-induced colitis group compared with the control group. Conversely, administration with TFA significantly inhibited the expression of the aforementioned 

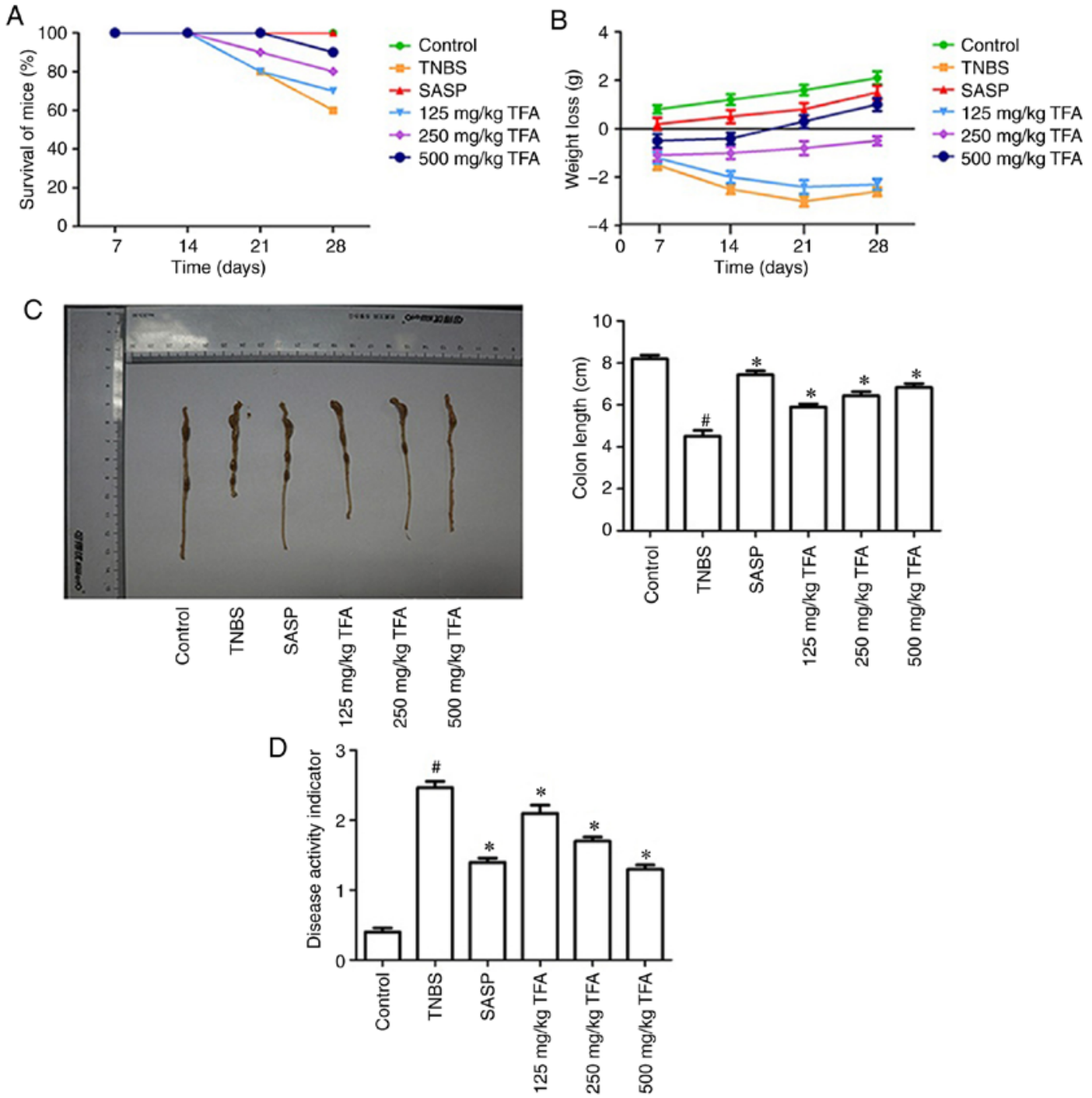

Figure 3. TFA ameliorates the progression TNBS-induced colitis in mice. (A) The survival of mice was measured. (B) Body weight loss was evaluated following TNBS-induced colitis. (C) A representative view of colon morphology. (D) The disease activity indicator scores were counted. Each experiment was performed in triplicate and results are expressed as the mean \pm standard deviation $(n=3)$. ${ }^{\#} \mathrm{P}<0.05$ vs. control group, ${ }^{*} \mathrm{P}<0.05$ vs. TNBS group. TFA, total flavone of Abelmoschus manihot L. Medic; SASP, salazosulfapyridine; TNBS, 2,4,6-trinitrobenzene sulfonic acid.

proteins (Fig. 6A). In addition, TNBS inhibited the expression of p-p65 and p52, while SASP or TFA significantly reversed this effect, which indicated that TFA could block the NF- $\kappa$ B signal pathway (Fig. 6A). Additionally, the associated proteins of the MAPK signaling pathway were analyzed. The results suggested that the expression levels of p-ERK1/2, p-JNK and p-p38 were significantly increased in the colon tissues in the TNBS-induced colitis group, while SASP or TFA suppressed the expression of these proteins (Fig. 6B). These results indicated that TFA could inhibit the activation of the NF- $\mathrm{KB}$ and MAPK signaling pathways in TNBS-induced colitis.

Effects of TFA on RAW264.7 cell cytotoxicity. The cytotoxicity of TFA was evaluated using a CCK-8 assay. RAW264.7 cells were incubated with TFA of various concentrations $(0,5$, $10,25,50,75,100,150$ and $200 \mu \mathrm{g} / \mathrm{ml})$. The results reveled no significant changes in cell viability, indicating that TFA was not cytotoxic at $\leq 200 \mu \mathrm{g} / \mathrm{ml}$ (Fig. 7A). Therefore, 50, 100 and $200 \mu \mathrm{g} / \mathrm{ml}$ were selected for subsequent in vitro analyses.
TFA decreases the production of inflammatory cytokines in LPS-induced RAW264.7 cells. To further study the effects of TFA in vitro, ELISA was performed to evaluate the production of inflammatory cytokines in LPS-stimulated RAW264.7 cells. The results demonstrated that LPS significantly promoted the levels of inflammatory cytokines in RAW264.7 cells compared with the control, including TNF- $\alpha$, IFN- $\gamma$, IL-6, IL-1 $\beta$, IL-12 and IL-17. However, SASP or TFA treatment significantly suppressed cytokine production compared with LPS treatment (Fig. 7B).

TFA inhibits the NF- $\kappa B$ and MAPK signaling pathways in LPS-stimulated RAW264.7 cells. To provide further insight into the mechanisms of TFA, the activation of the NF- $\mathrm{KB}$ and MAPK signaling pathways in LPS-stimulated RAW264.7 macrophages was evaluated by western blotting. The results showed that the expression levels of $\mathrm{p}-\mathrm{IKK} \alpha / \beta / \gamma, \mathrm{I} \kappa \mathrm{B} \alpha$ and p100 were significantly increased by LPS treatment, but were downregulated by TFA in a dose-dependent manner. Additionally, SASP and TFA significantly promoted the 



$500 \mathrm{mg} / \mathrm{kg}$ TFA
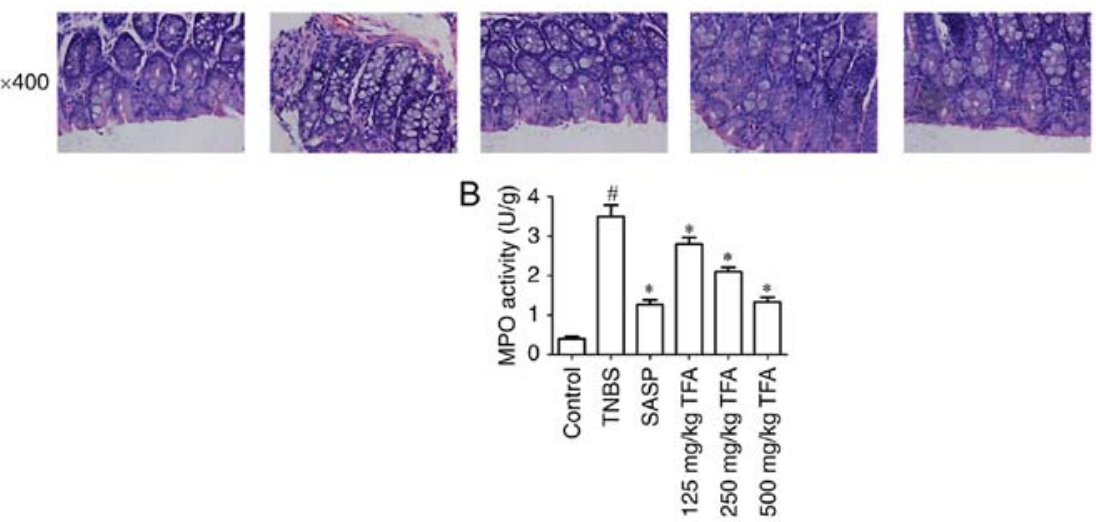

Figure 4. TFA improves histopathological alterations in TNBS-induced colitis. (A) Paraffin embedded colon sections were stained with hematoxylin and eosin the assessment of epithelial damage of colitis mice. Images (magnification, x200 and 400) of the colon of mice in different groups were collected. The colons of mice in the control group exhibited a normal structure without damage; however, in the TNBS model group, the colon exhibited glandular defects, mucosal ulcerations and inflammatory cell infiltration, but these alterations were attenuated to varying degrees by treatment with $125,250 \mathrm{and} 500 \mathrm{mg} / \mathrm{kg}$ TFA or SASP. Arrows indicate the aforementioned features observed in each group. (B) The levels of MPO activity in colon tissues were evaluated. ${ }^{~} \mathrm{P}<0.05$ vs. control group, "P<0.05 vs. TNBS group. Each experiment was performed in triplicate. TFA, total flavone of Abelmoschus manihot L. Medic; MPO, myeloperoxidase; SASP, salazosulfapyridine; TNBS, 2,4,6-trinitrobenzene sulfonic acid.


Figure 5. TFA suppresses the production of inflammation cytokines in TNBS-induced colitis. ELISAs were performed to detect the production of cytokines, including TNF- $\alpha$, IFN- $\gamma$, IL-6, IL-1 $\beta$, IL-12 and IL-17, in the sera and colon tissues. ${ }^{*} \mathrm{P}<0.05$ vs. control group, ${ }^{*} \mathrm{P}<0.05$ vs. TNBS group. Each experiment was performed in triplicate. IL, interleukin; SASP, salazosulfapyridine; TFA, total flavone of Abelmoschus manihot L. Medic; TNF- $\alpha$, tumor necrosis factor- $\alpha$; TNBS, 2,4,6-trinitrobenzene sulfonic acid. 

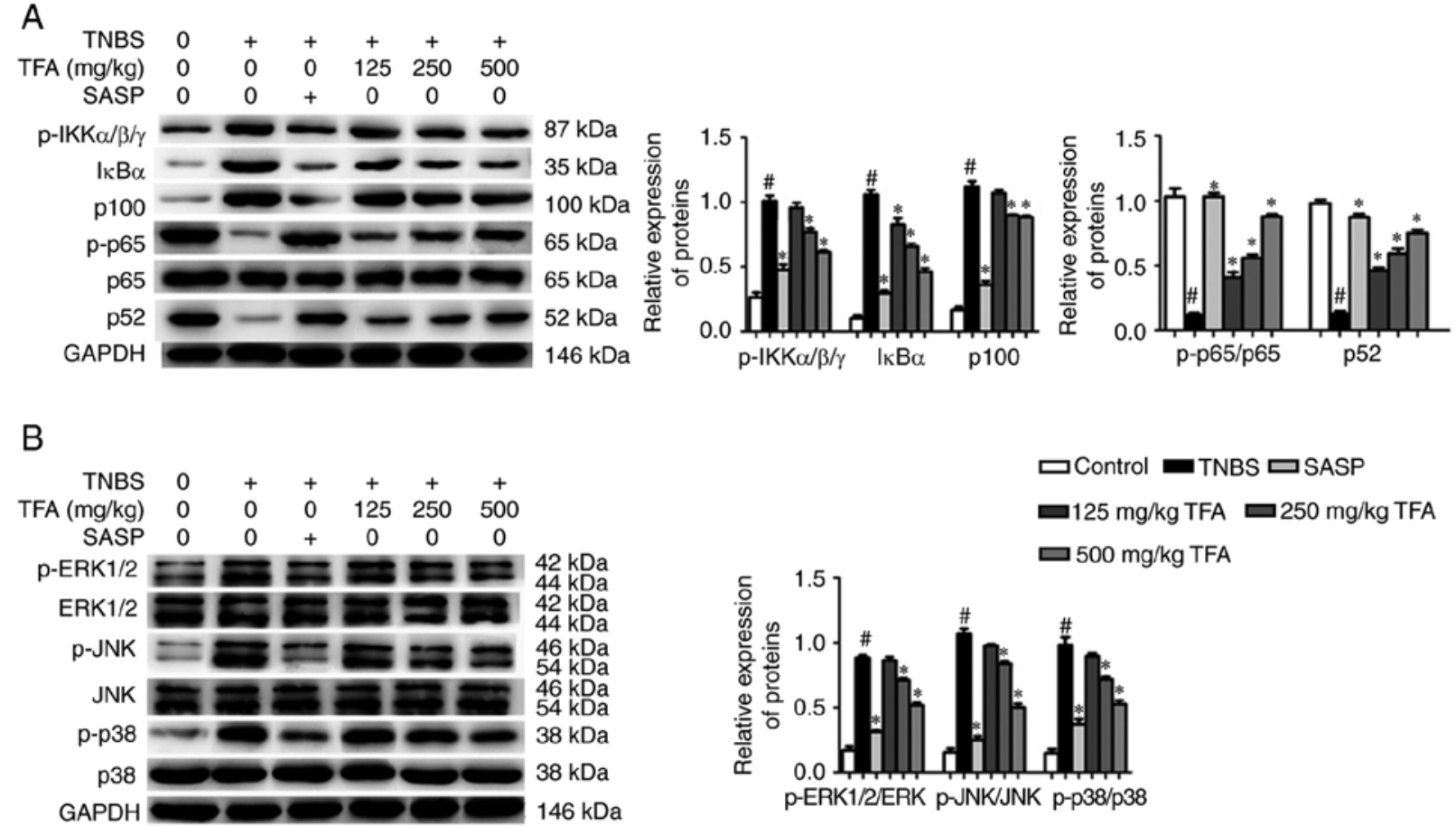

Figure 6. TFA inhibits the activation of the NF- $\mathrm{KB}$ and MAPK signaling pathways in TNBS-induced colitis. (A) Western blotting was conducted to determine the expression of related-proteins of the NF- $\mathrm{KB}$ signaling pathway in colon tissues. Quantification of protein expression in each group was presented. (B) The expression of related-proteins of the MAPK signaling pathway was evaluated by western blotting. Quantification of protein expression in each group was presented. ${ }^{~} \mathrm{P}<0.05$ vs. control group, ${ }^{*} \mathrm{P}<0.05$ vs. TNBS group. ERK, extracellular signal-regulated kinase; IKK, I $\mathrm{B}$ B $\alpha$ kinase; JNK, c-Jun N-terminal kinase;

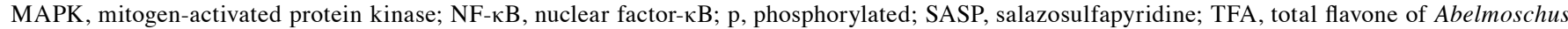
manihot $\mathrm{L}$. Medic; TNBS, 2,4,6-trinitrobenzene sulfonic acid.
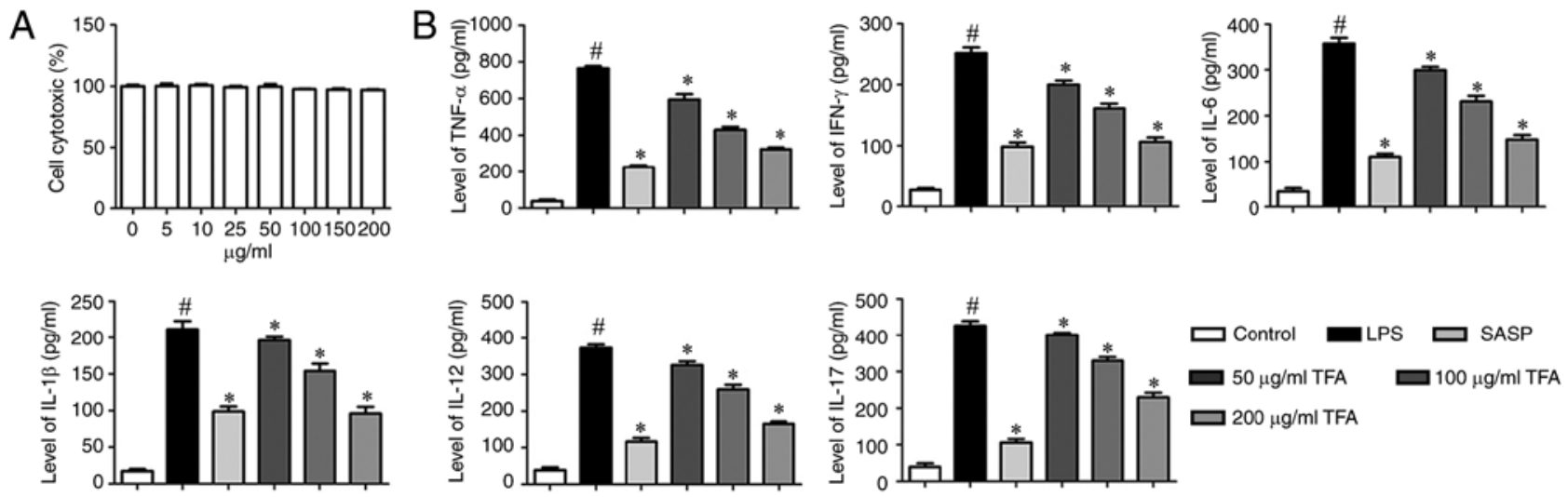

Figure 7. TFA decreases the production of inflammatory cytokines in LPS-induced macrophage RAW264.7 cells. (A) RAW264.7 cells were incubated with TFA of various concentrations $(0,5,10,25,50,75,100,150$ and $200 \mu \mathrm{g} / \mathrm{ml})$. Then, cell viability was evaluated by a Cell Counting Kit-8 assay. (B) RAW 264.7 cells were stimulated with LPS $(1 \mu \mathrm{g} / \mathrm{ml})$ for $24 \mathrm{~h}$ in the presence or absence various TFA concentrations or SASP. The supernatants were harvested and analyzed by ELISA. The levels of inflammatory factors were presented. ${ }^{*} \mathrm{P}<0.05 \mathrm{vs}$. control group, ${ }^{*} \mathrm{P}<0.05 \mathrm{vs}$. TNBS group. Each experiment was performed in triplicate. IL, interleukin; LPS, lipopolysaccharide; SASP, salazosulfapyridine; TFA, total flavone of Abelmoschus manihot L. Medic; TNBS, 2,4,6-trinitrobenzene sulfonic acid; TNF- $\alpha$, tumor necrosis factor- $\alpha$.

expression of p-p65 and p52 in RAW264.7 macrophages in a dose-dependent manner, which was reversed by LPS (Fig. 8A). In addition, we investigated the effects of TFA on the activation of MAPK signaling pathway. The results indicated that LPS significantly upregulated phosphorylation of ERK1/2, JNK and p38 compared with the control, while SASP or TFA decreased the expression of these proteins. Total protein expression levels of ERK1/2, JNK and p38 were markedly altered (Fig. 8B).

\section{Discussion}

$\mathrm{CD}$ is an intestinal inflammatory disease, which can occur in any region of the gastrointestinal tract, particularly the terminal ileum and right colon (32). CD and chronic nonspecific ulcerative colitis are collectively referred to as inflammatory bowel disease. Its clinical manifestations include abdominal pain, diarrhea, intestinal obstruction, and other enteral manifestations, such as fever and malnutrition (33). This disease is also 

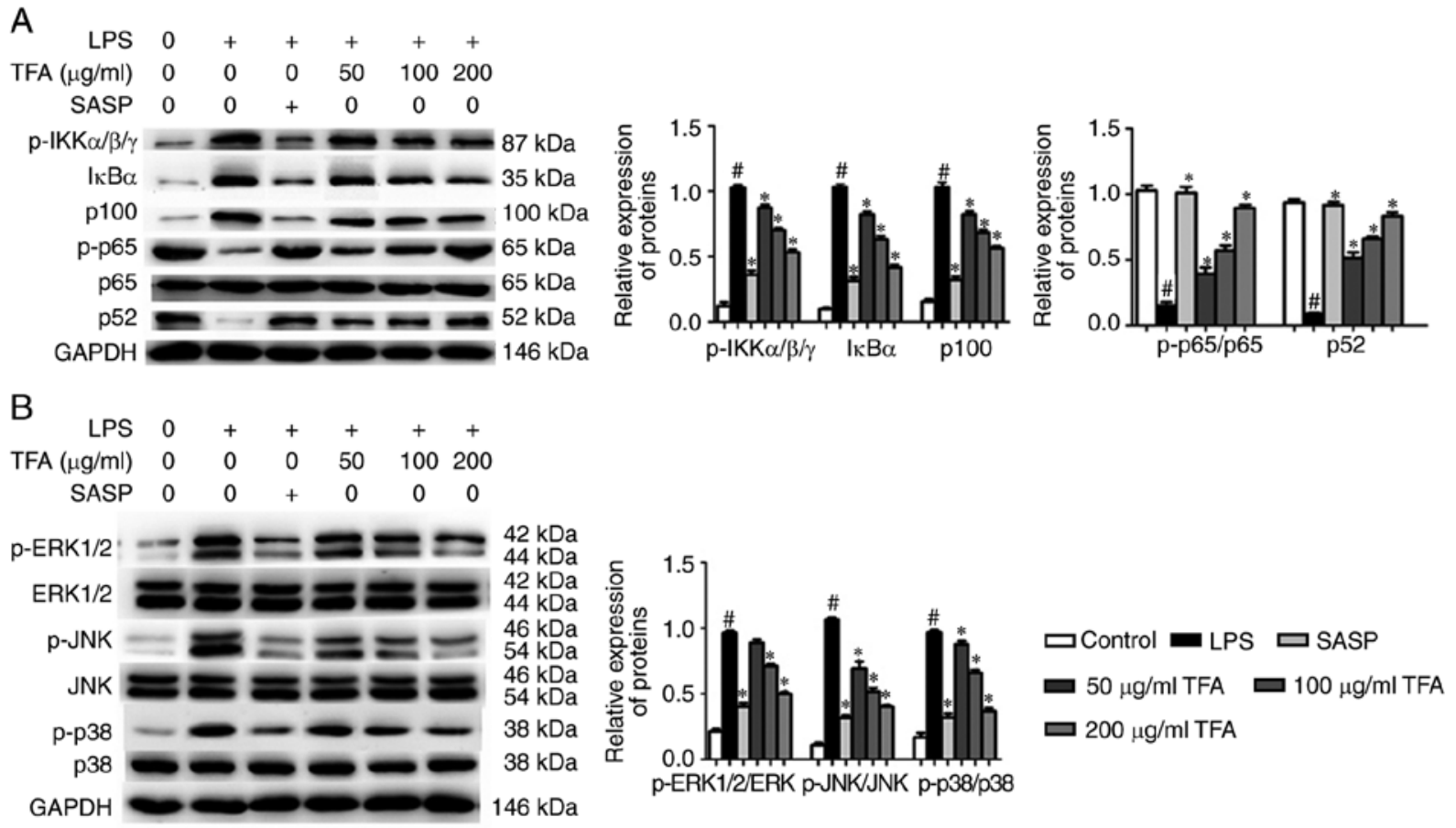

Figure 8. TFA suppresses the NF- $\mathrm{B}$ and MAPK signaling pathways in LPS-stimulated RAW264.7 cells. (A) Western blotting was adopted to determine the expression of related-proteins of the NF- $\mathrm{kB}$ signaling pathway in LPS-stimulated RAW264.7 cells. Quantification of expression levels of proteins in each group was presented. (B) The expression levels of related-proteins of the MAPK signaling pathway in LPS-stimulated RAW264.7 cells were evaluated by western blotting. Quantification of expression levels of proteins in each group was presented. ${ }^{\text {"P }}<0.05$ vs. control group, ${ }^{*} \mathrm{P}<0.05$ vs. TNBS group. ERK,

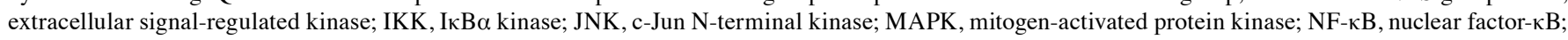
p, phosphorylated; SASP, salazosulfapyridine; TFA, total flavone of Abelmoschus manihot L. Medic; TNBS, 2,4,6-trinitrobenzene sulfonic acid.

known as localized enteritis, localized ileocolitis, segmental enteritis and granulomatous enteritis (34). The pathological features are granulomatous inflammation, fibrosis and ulceration, ulcers, paving stone changes and intestinal stenosis in the digestive tract (34). At present, the treatment of CD is mainly comprises drugs, including glucocorticoids, salicylic acid preparations, immunosuppressive agents, antibiotics, methotrexate and biological agents (35-38). In addition, the long-term use of western medicine in treating $C D$ was proposed to be unsatisfactory with high recurrence rates and side effects following treatment (39).

Traditional Chinese medicine has a history of thousands of years and has made notable contributions to human health (40). It has markedly improved the treatment of intestinal diseases. The intervention of $\mathrm{CD}$ with traditional Chinese medicine has various targets and mechanisms to inhibit intestinal inflammation, and restores the intestinal mucosal immune balance (41). This field of research has gained increasing attention and has become an important research direction in the treatment of CD. A. manihot L. Medic is a traditional herbal medicine, which has been used as a neuroprotective drug for cerebral ischemic reperfusion injury (17). TFA is the main active ingredient, which has been used as an anti-inflammatory and myocardial ischemia-protective drug. In the present study, TFA as observed to ameliorate TNBS-induced colitis weight loss and reductions in colon length. Additionally, the colons of TNBS-induced in mice pre-treated with TFA exhibited only mild inflammation.

$\mathrm{CD}$ is characterized by $\mathrm{T}$ cell activation and inflammatory cell aggregation in the mucosa (42-44). In the process of occurrence and development of $\mathrm{CD}$, cytokines can aggravate inflammation through various mechanisms, resulting in chronic intestinal tissue injury (45). The present study reported that the administration of TFA in mice with TNBS-induced colitis led to a significant decrease in the production of TNF- $\alpha$, IFN- $\gamma$, IL-6, IL-1 $\beta$, IL-12 and IL-17 in the sera and colon tissues. In addition, we found that TFA treatment significantly inhibited the expression of inflammatory factors in LPS-induced RAW264.7. These results indicated that TFA may serve a role in the modulation of cytokine production under conditions of colonic inflammation.

The NF- $\mathrm{\kappa B}$ signaling pathway is a predominant pathway involved in the regulation of immune and inflammatory responses (46). NF- $\kappa \mathrm{B}$, which is markedly upregulated in patients with $\mathrm{CD}$, has been identified to serve an important role in the regulation of mucosal inflammation (47). MAPK signaling, including ERK1/2, JNKs, and p38 MAPK, can mediate cell growth, differentiation and death via regulation of the expression of numerous genes (48). A previous study demonstrated that MAPK signaling could mediate the LPS-stimulated expression of inflammation mediators (49). Additionally, inhibition of MAPK signaling pathway could reduce inflammation (50). In the present study, we reported that TFA inhibited the activation of the NF- $\mathrm{KB}$ and MAPK signaling pathways.

In summary, TFA notably attenuated colon damage and inflammation associated with TNBS-colitis. Our findings indicated the protective effects of TFA on colon health, possibly via inhibition of macrophages by suppression of the NF- $\mathrm{KB}$ and MAPK signaling pathways. The results of the 
present study may provide a basis for the development of novel therapeutic approaches with TFA in treating patients CD.

\section{Acknowledgements}

Not applicable.

\section{Funding}

The present study was supported by the National Natural Science Foundation of China (grant no. 81573978). This study was also supported by the Priority Academic Program Development of Jiangsu Higher Education Institutions and Jiangsu Province Special Program of Medical Science (grant no. BL2014100) and by the Peak Academic Talents plan (grant no. BRA2017536) of the Jiangsu Province Hospital of Chinese Medicine.

\section{Availability of data and materials}

All data generated or analyzed during this study are included in this published article.

\section{Authors' contributions}

DZ, PZ, YGC made substantial contributions to the design of the present study. YL, YS, JYZ, FJ, TC and BLY performed the experiments.. DZ and YGC wrote the manuscript. All authors read and approved the final manuscript.

\section{Ethics approval and consent to participate}

The animal experiments were approved by the Institutional Ethics Committee of Nanjing University of Chinese Medicine.

\section{Patient consent for publication}

Not applicable.

\section{Competing interests}

The authors declare that they have no competing interests.

\section{References}

1. Manning G, Whyte DB, Martinez R, Hunter T and Sudarsanam S The protein kinase complement of the human genome. Science 298: 1912-1934, 2002.

2. Podolsky DK: Inflammatory bowel disease. N Engl J Med 347: 417-429, 2002.

3. Matricon J, Barnich N and Ardid D: Immunopathogenesis of inflammatory bowel disease. Self Nonself 1: 299-309, 2010.

4. Strober W, Fuss I and Mannon P: The fundamental basis of inflammatory bowel disease. J Clin Investig 117: 514-521, 2007.

5. Cominelli F: Cytokine-based therapies for Crohn's disease-New paradigms. N Engl J Med 351: 2045-2048, 2004.

6. Lv QK, Liu JX, Li SN, Gao YJ, Lv Y, Xu ZP, Huang BX, Xu SY, Yang DX, Zeng YL, et al: Mycophenolate mofetil modulates differentiation of Th1/Th2 and the secretion of cytokines in an active crohn's disease mouse model. Int J Mol Sci 16: 26654-26666, 2015 .

7. Orenstein R: Anti-interleukin-12 antibody for active Crohn's disease. N Engl J Med 352: 627-628, 2005

8. Sartor RB: Mechanisms of disease: Pathogenesis of Crohn's disease and ulcerative colitis. Nat Clin Pract Gastroenterol Hepatol 3: 390-407, 2006.
9. Luo JH, Zhang CY, Lu CY, Guo GH, Tian YP and Li YL: Serum expression level of cytokine and chemokine correlates with progression of human ovarian cancer. Eur J Gynaecol Oncol 38: 33-39, 2017.

10. Atreya I, Atreya R and Neurath MF: NF-kappaB in inflammatory bowel disease. J Intern Med 263: 591-596, 2008.

11. Kyriakis JM and Avruch J: Mammalian mitogen-activated protein kinase signal transduction pathways activated by stress and inflammation. Physiol Rev 81: 807-869, 2001.

12. Kim EK and Choi EJ: Pathological roles of MAPK signaling pathways in human diseases. Biochim Biophys Acta 1802: 396-405, 2010.

13. Mi Y, Zhang D, Jiang W, Weng J, Zhou C, Huang K, Tang H, Yu Y, Liu X, Cui W, et al: miR-181a-5p promotes the progression of gastric cancer via RASSF6-mediated MAPK signalling activation. Cancer Lett 389: 11-22, 2017.

14. Liao T, Wen D, Ma B, Hu JQ, Qu N, Shi RL, Liu L, Guan Q, Li DS and Ji QH: Yes-associated protein 1 promotes papillary thyroid cancer cell proliferation by activating the ERK/MAPK signaling pathway. Oncotarget 8: 11719-11728, 2017.

15. Docena G, Rovedatti L, Kruidenier L, Fanning A, Leakey NAB, Knowles CH, Lee K, Shanahan F, Nally K, Mclean PG, et al: Down-regulation of p38 mitogen-activated protein kinase activation and proinflammatory cytokine production by mitogen-activated protein kinase inhibitors in inflammatory bowel disease. Clin Exp Immunol 162: 108-115, 2010.

16. Hommes D, van den Blink B, Plasse T, Bartelsman J, Xu C, Macpherson B, Tytqat G, Peppelenbosch M and Van Deventer S: Inhibition of stress-activated MAP kinases induces clinical improvement in moderate to severe Crohn's disease. Gastroenterology 122: 7-14, 2002.

17. Wen JY and Chen ZW: Protective effect of pharmacological preconditioning of total flavones of Abelmoschl manihot on cerebral ischemic reperfusion injury in rats. Am J Chin Med 35: 653-661, 2007.

18. Lai X, Liang H, Zhao Y and Wang B: Simultaneous determination of seven active flavonols in the flowers of Abelmoschus manihot by HPLC. J Chromatogr Sci 47: 206-210, 2009.

19. Wang XR, Zhou ZH, Du AQ and Huang ZM: Studies on the flavonol constituents of Abelmoschus manihot L. Medic Chin J Nat Med 2: 91-93, 2004.

20. Fan L, Dong LY, Chen ZW, Cen DY, Jiang Q and Ma CG: Analgesic effect of total flavone of Abelmoschlmanihot L Medic. Pharmacol Clin Chin Mater Med 19: 12-14, 2003.

21. Zhou L, An XF, Teng SC, Liu JS, Shang WB, Zhang AH, Yuan YG and Yu JY: Pretreatment with the total flavone glycosides of flos Abelmoschus manihot and hyperoside prevents glomerular podocyte apoptosis in streptozotocin-induced diabetic nephropathy. J Med Food 15: 461-468, 2012.

22. Gao S, Fan L, Dong LY, Zhao WZ and Chen ZW: Effect of TFA on cell apoptosis in MCAO rats. Chin Pharmacol Bull 19: 704-707, 2003.

23. Gu P, Zhu L, Liu Y, Zhang L, Liu J and Shen H: Protective effects of paeoniflorin on TNBS-induced ulcerative colitis through inhibiting NF-kappaB pathway and apoptosis in mice. Int Immunopharmacol 50: 152-160, 2017.

24. Zhu L, Gu P and Shen H: Protective effects of berberine hydrochloride on DSS-induced ulcerative colitis in rats. Int Immunopharmacol 68: 242-251, 2019.

25. Zhu L, Gu P and Shen H: Gallic acid improved inflammation via NF- $\kappa$ B pathway in TNBS-induced ulcerative colitis. Int Immunopharmacol 67: 129-137, 2019.

26. Fu K, Lv X, Li W, Wang Y, Li H, Tian W and Cao R: Berberine hydrochloride attenuates lipopolysaccharide-induced endometritis in mice by suppressing activation of NF- $\mathrm{KB}$ signal pathway. Int Immunopharmacol 24: 128-132, 2015.

27. Lee JC, Biasci D, Roberts R, Gearry RB, Mansfield JC, Ahmad T, Prescott NJ, Satsangi J, Wilson DC, Jostins L, et al: Genome-wide association study identifies distinct genetic contributions to prognosis and susceptibility in Crohn's disease. Nat Genet 49: 262-268, 2017.

28. Wu F, Guo NJ, Tian H, Marohn M, Gearhart S, Bayless TM, Brant SR and Kwon JH: Peripheral blood MicroRNAs distinguish active ulcerative colitis and Crohn's disease. Inflamm Bowel Dis 17: 241-250, 2011.

29. Gałecki P, Gałecka E, Maes M, Chamielec M, Orzechowska A, Bobińska K, Lewiński A and Szemraj J: The expression of genes encoding for COX-2, MPO, iNOS, and sPLA2-IIA in patients with recurrent depressive disorder. J Affect Disord 138: 360-366, 2012 . 
30. Nunberg MY, Werner L, Kopylov U, Haberman Y, Lahad A, Weiss B and Shouval DS: Impaired IL-10 receptor mediated suppression in monocyte from patients with Crohn's disease. J Pediatr Gastroenterol Nutr 66: 779-784, 2018.

31. Okayasu I, Hatakeyama S, Yamada M, Ohkusa T, Inagaki Y and Nakaya R: A novel method in the induction of reliable experimental acute and chronic ulcerative colitis in mice. Gastroenterology 98: 694-702, 1990.

32. Pan T, Guo HY, Zhang H, Liu AP, Wang XX and Ren FZ: Oral administration of Lactobacillus paracasei alleviates clinical symptoms of colitis induced by dextran sulphate sodium salt in BALB/c mice. Benef Microbes 5: 315-322, 2014.

33. Dou W, Zhang J, Ren G, Ding L, Sun A, Deng C, Wu X, Wei X, Mani S and Wang Z: Mangiferin attenuates the symptoms of dextran sulfate sodium-induced colitis in mice via NF- $\kappa$ B and MAPK signaling inactivation. Int Immunopharmacol 23: 170-178, 2014.

34. Lian L, Huang Q, Zhang L, Qin H, He X, He X, Ke J, Xie M and Lan P: Anti-fibrogenic potential of mesenchymal stromal cells in treating fibrosis in Crohn's Disease. Dig Dis Sci 63: 1821-1834, 2018.

35. Feagan BG, Rutgeerts P, Sands BE, Hanauer S, Colombel JF, Sandborn WJ, Van Assche G, Axler J, Kim HJ, Danese S, et al: Vedolizumab as induction and maintenance therapy for ulcerative colitis. N Engl J Med 369: 699-710, 2013

36. Franke A, Balschun T, Karlsen TH, Sventoraityte J, Nikolaus S, Mayr G, Domingues FS, Albrecht M, Nothnagel M Ellinghaus D, et al: Sequence variants in IL10, ARPC2 and multiple other loci contribute to ulcerative colitis susceptibility. Nat Genet 40: 1319-1323, 2008.

37. Cohen P, Pagnoux C, Mahr A, Arène JP, Mouthon L, Le Guern V, André MH, Gayraud M, Jayne D, Blöckmans D, et al: Churg-Strauss syndrome with poor-prognosis factors: A prospective multicenter trial comparing glucocorticoids and six or twelve cyclophosphamide pulses in forty-eight patients. Arthritis Rheum 57: 686-693, 2007.

38. Lichtenstein GR, Diamond RH, Wagner CL, Fasanmade AA, Olson AD, Marano CW, Johanns J, Lang Y and Sandborn WJ: Clinical trial: Benefits and risks of immunomodulators and maintenance infliximab for IBD-subgroup analyses across four randomized trials. Aliment Pharmacol Ther 30: 210-226, 2009.
39. Vetter M and Neurath MF: Treatment perspectives in Crohn's disease. Digestion 98: 135-142, 2018.

40. Geng CA, Yang TH, Huang XY, Yang J, Ma YB, Li TZ, Zhang XM and Chen JJ: Anti-hepatitis B virus effects of the traditional Chinese herb Artemisia capillaris and its active enynes. J Ethnopharmacol 224: 283-289, 2018.

41. Sun J, Shen X, Dong J, Wang H, Zuo L, Zhao J, Zhu W, Li Y, Gong J and Li J: Tripterygium wilfordii Hook F as maintenance treatment for Crohn's disease. Am J Med Sci 350: 345-351, 2015.

42. Izutani R, Loh EY, Reinecker HC, Ohno Y, Fusunyan RD, Lichtenstein GR, Rombeau JL and Macdermott RP: Increased expression of interleukin-8 mRNA in ulcerative colitis and Crohn's disease mucosa and epithelial cells. Inflamm Bowel Dis 1: 37-47, 1995

43. Fine SN: Adalimumab for the treatment of fistulas in patients with Crohn's disease. Inflamm Bowel Dis 17: 667-668, 2011.

44. Peyrin-Biroulet L, Oussalah A, Williet N, Pillot C, Bresler L and Bigard MA: Impact of azathioprine and tumour necrosis factor antagonists on the need for surgery in newly diagnosed Crohn's disease. Gut 60: 930-936, 2011.

45. Bamias G and Cominelli F: Cytokines and intestinal inflammation. Curr Opin Gastroenterol 32: 437-442, 2016.

46. Lawrence $\mathrm{T}$ and Fong $\mathrm{C}$ : The resolution of inflammation: Anti-inflammatory roles for NF-kappaB. Int J Biochem Cell Biol 42: 519-523, 2010.

47. Han YM, Koh J, Kim JW, Lee C, Koh SJ, Kim B, Lee KL, Im JP and Kim JS: NF-kappa B activation correlates with disease phenotype in Crohn's disease. PLoS One 12: e0182071, 2017.

48. Karin M: Mitogen activated protein kinases as targets for development of novel anti-inflammatory drugs. Ann Rheum Dis 63 (Suppl 2): ii62-ii64, 2004.

49. Cuadrado A and Nebreda AR: Mechanisms and functions of $\mathrm{p} 38$ MAPK signaling. Biochem J 429: 403-417, 2010.

50. Peroval MY, Boyd AC, Young JR and Smith AL: A critical role for MAPK signaling pathways in the transcriptional regulation of toll like receptors. PLoS One 8: e51243, 2013. 